\title{
Research on Teaching Reform and Innovation of Animation Major Oriented by Project Teaching Method
}

\author{
Yongjie Li, Tingting Wei \\ Department of Art \& Design, Guangxi Technological College of Machinery and Electricity, Nanning, 530007, \\ China
}

Keywords: Teaching reform and innovation, Animation major, Project teaching method

\begin{abstract}
The traditional teaching model of animation major pays too much attention to the study of theory, but ignores the important role of practice. Project teaching method can solve this difficult problem effectively and keep the consistency of teaching and market. This paper analyzes the advantages and conditions of project teaching and expounds the important contents of project preparation, project implementation and project evaluation to provide some references for the relevant researchers.
\end{abstract}

\section{Introduction}

The project teaching method transforms the knowledge content in the traditional discipline system into several teaching items, revolves the project organization and carries on the teaching, enables the student to participate, the experience, the sentiment, the proof, the inquiry directly. Including: teachers and students through joint implementation of a complete project work to carry out teaching activities; students in cooperation with teachers under the auspices of the working group, organized by the completion of the project; work should take the initiative and learning process to become a person involved in the creation of practical activities, not focusing on the final results, but the completion of the project process. Animation is the abbreviation and abbreviation of animation and cartoon, because now the country supports the animation industry, so this word is popular. With the development of modern media technology, the relationship between animation and comics becomes more and more close, and they are often integrated into animation. Although nearly two years of domestic animation professional colleges and universities have many, the number of students still in short supply, animation students can successfully find a job. However, most people are engaged in the production of technical work, and cannot be very good to achieve the best allocation of talent. The biggest reason is that there is not the most effective exercise in school, so that animation graduates should start with technology. And the biggest advantage of project teaching is to be able to create a variety of talent, not the result is the whole class or all professional animation industry technical workers. China's animation industry started earlier than in Europe and Japan and South Korea, and has made great achievements, but due to the special historical reasons, resulting in China's animation industry has been lagging, now in the ensuing problems also spare no effort to catch up. The lack of good works, the lack of classical roles, and so on, are not to be ignored. China's animation companies tend to outsource the main, less original animation, making the domestic animation industry chain appears scarce. The lack of talent is the root cause, and the teaching of college students is the root of the problem. The teaching reform of animation major is imperative.

\section{Advantages and Conditions of Project Teaching Method}

Advantages. The most talented person in the animation industry is not an operator, but an innovator, while higher vocational colleges are like a factory line for training talents. Students are finished products, not products. Often students after entering the enterprise can only do the simplest 
operation of software outsourcing, animation design students to understand the main production, not only the operation design, but they do not know the nature only at the bottom of innovation. Project teaching is the teaching content between the teaching courses and the whole course of the mutual connection, teaching content is no longer a step, but from the overall effect of rational design and analysis of the production process, and full of aesthetic art throughout. This will not only train students' ability in design and production, but also cultivate students' ability to innovate and create. Project-based teaching can take a course as a big project, and the chapter is sub - item. Students can also be considered in all the courses they need to study at school. Different courses are allocated according to their position and study time. Each related course is a sub item. In this way, from the whole, the scattered so that the curriculum system is more perfect. Students are also more aware of the interaction between the courses and the overall coherence of the learning process. In this way, the phenomenon of repetition and disconnection during study will be eliminated, and the professional courses will be closely linked. Any professional cannot exist without the market, all professional learning in the end is for the market services, animation professional is also true. In the process of teaching, animation majors need rich theoretical knowledge to guide, and the formation of rich theoretical knowledge is based on many practical basis, and practical creation is the foundation. Based on practice, with abundant theoretical knowledge, it is the correct way of teaching. Animation teaching requires that the teaching content should take the market as a weathervane, conform to the development of the market and keep up with the trend of the times, which means that teaching cannot be divorced from the development of the market. Always keep pace with market trends. Project driven teaching is to promote the teaching link and the enterprise, the market can be closely linked, the common project enterprise, market making in the practice of teaching, so that students can understand the working process in advance.

Conditions. In the link of project-based teaching, teachers are the most important part. The level of teachers has a direct bearing on the quality of project-based teaching. The first thing we should do is that teachers should understand the deep meaning of project teaching. Teachers should discard the most traditional ways of imparting knowledge and accept this way of thinking. First, change your role: This is also a topic that is often discussed, that is, break through the one to many situation and integrate the teacher into the student's team. Secondly, the correct guidance of students, most students have become accustomed to the traditional teaching model, this change will have a negative impact. Finally, pay attention to the teacher's teaching attitude: the teacher's attitude will eventually be reflected in the students' works. Because the teacher is also a participant in the project, so the teachers' practical ability directly affects the students for the completion of this project the size of confidence, it is more important for a student to ensure that the teacher's trust is the size of interest. Animation industry is a new industry. Therefore, it is necessary to form a lack of qualified teachers and animation skills. Most teachers are from the relevant professional transformation, and animation for the entire process is still relatively new. We can see that to really get into the animation industry, it is not enough to master one of the pieces, and we must master it comprehensively to coordinate all aspects. A teacher is like a dispatcher who has a thorough and systematic study to carry out a reasonable division of labor according to the students' specialty so that the project can be finished more efficiently. Teachers are not the dominant position in teaching, but they are the guides, supervisors and supervisors in the process of student learning, and students are motivated. Animation project teaching, more to do is teachers and students, students and student's exchanges, is to cultivate the initiative to learn, so that the role of teachers and students in fact have undergone great changes. Each student is a member of the animation and related projects, can contribute to the collective strength of their own, are the owners of this project, are related to the success or failure of the project. This responsibility allows students to feel a sense of pressure that can be translated into a great interest after proper guidance. 


\section{Implementation Steps of Project Teaching Method}

Project Preparation. Clear the specific requirements of the course is sailing rudder, and determine the project is the key to the training course teaching. There are many forms of curriculum project: the exchange of teachers, school enterprise joint training, professional teaching, enterprise competition, academic exchanges, can be selected according to the resource. The double tutor system refers to the university teachers and mentors to establish project overall requirements, including content requirements, production cycle and quality requirements, time requirements, rendering the output format and size requirements. According to the company division process to develop project management manual, the attendance, progress tracking, project handover links do detailed provisions, strict implementation of the class attendance card attendance system, results will be converted into normal scores; with green, blue, yellow and red colors of green label production, said it had completed the transfer that is blue; Huang said the need to modify the production; adjustment; red said seriously slow or be re produced); handover of the project implementation team leader responsibility system, each team leader is responsible for the distribution of issued production tasks, and timely transfer of production of content has been completed, signed the handover, the right of clear, easy to manage. After the project task is determined by the students themselves, develop work plans, and to determine the working steps and procedures that enable students to recognize the dominant position and importance in the learning process itself, thus greatly mobilize the initiative of learning, so that it can take the initiative to learn, enhance their ability of finding and solving problems. The teacher may be guided and revised in accordance with the preliminary plan prepared by the student. Teachers give constructive advice on the topic and focus on the characteristics of the common materials for different teams to make plans for the primaries. Project proposal to the team as a unit for a report by the director, mainly expounds the script outline, art design, material selection and project schedule, the class combination of peer assessment and teacher comments, the creative team to provide useful advice.

Project Implementation. The animation company management system should be introduced to the project production, and the director should be responsible for the project management. Head of supervision of the production schedule and quality, production enterprises at the beginning of two the teacher invited lectures, introduce the industry forefront and key technology of dynamic sharing of experience, the teachers act as technical adviser and artistic direction, teaching the basic core skills, such as tool tips, light shooting skills, software operation skill, editing technology, real-time control of each production team the progress of eliminating confusion, provide solutions in the team encounter cannot solve the difficulties, make each link of high quality video creation to effectively promote the seamless link between. Animated short film music encourages students to invite music majors, composers, students and professionals to participate. In order to ensure the production schedule and quality, carry out the examination and a film examination, check and review process to company employees to participate in the mid-term examination, mainly to verify the artistic style and quality requirements and schedule is completed in accordance with the curriculum requirements, work plan the next step is not reasonable, first check the main early film synthesis effect, propose specific amendments. The teachers in this link must be timely insight into the project problems, the introduction of enterprise management mode, the students every day on time every day after class attendance, registration and update project schedule, every Monday morning regular project meeting, discuss the project implementation process, the confusion, the problems need to be solved and the next step to clarify the vision project. The project takes students as the main part and gives full play to the subjective initiative of the students. The project pays attention to give full play to the students' subjective initiative, teachers provide the general framework and reference materials of the project, and make some suggestions on the steps and methods to achieve the final results. According to the information provided by the teachers, students search for materials, find ways, design proposals and implement steps of specific effects, and finally achieve certain results. Teachers are responsible for checking the design of students, pointing out shortcomings and omissions, and asking students to sum up experience and improve efficiency. 
Project Evaluation. Based on the results of the project, does not meet the requirements of footage returned for it within a specified period and then modify complete acceptance, acceptance in the enterprise and students to finally complete the repair interaction, students must realize the understanding of the market evaluation rules. The final evaluation result of the project is to be verified by society. Enterprise project teaching pays attention to process and comprehensive assessment, and integrates practical ability and project ability into the scope of assessment. Student final score includes the following: evaluation of the project team leader, the content of the assessment for the number of tasks undertaken, the quality of the project completion, communication and cooperation ability, contribution to the project size. Assessment of the students, the assessment content for the completion of the project, the quality of the project, tasks and contributions to the size of the project base, the relevant rules and regulations, attendance, attendance and so on. Students may undertake some tasks in an animation project of the company and consult with several animation companies in Wuhan for students to practice in the company. Students learn, basically in accordance with the project teaching methods on campus, and then use the summer to the animation company to exercise. This will enable students to use animation skills in school work in the creation of practical work, so as to enable students to understand the animation process and market animation needs more clearly. At the same time, the college has established a complete filing system to record student achievement in the graduate archives. The teacher will be excellent films released to micro-blog, WeChat and other new media platforms, expand their exchanges and communication, and recommend to the local television broadcasting or at home and abroad to participate in professional competition, accept the inspection and evaluation of the society to get better promotion. Hire people involved in the industry view exchange, and their scores to the highest proportion, respect the needs and professional judgment, please tutor the interaction of the film industry and share experiences, to enable students to understand the industry standards and strive towards the open field of vision, for students, at the same time through the course of problems improve the project teaching, learn from experience.

\section{Conclusion}

Project teaching method runs through the whole university's learning cycle and students can learn and practice at the same time. In the process of participation in the project, students can find their own technical strengths according to their own expertise practice to determine the future direction of employment. Therefore, the project teaching method is an important thinking of the teaching reform of animation major.

\section{References}

[1] Xi Xiaoxi,Wang Qingyu, Zhang Xueqin. Research on Teaching Reform of Animation Course Based on Project Teaching Method [J]. Education Teaching Forum, 2017(8): 89-90.

[2] Sun Xing, Zha Jingjing. Analysis of the Reform and Development of the Teaching of Animation Major in Higher Vocational Colleges Based on Project Oriented Teaching [J]. Journal of JingDeZhen University, 2016, 31(6): 112-115.

[3] Zhao Han. Research on Personalized Group Division in the Project-Based Hierarchical Teaching in Animation Major [J]. Software Engineering, 2017, 20(4): 18-21.

[4] Wu Jun. Humble Opinions on the Exploration and Application of Project Methodology in Undergraduate Animation Practice Training Course, Take Material Animation as Example [J]. Art and Design, 2016(10): 147-149. 